\title{
Assessing the Impact of Changes on Design and Material of Howe Bridges by Finite Element Analysis
}

\author{
Jairo Aparecido Martins and Estaner Claro Romão
}

\section{ABSTRACT}

\begin{abstract}
This paper presents an investigation of changes on design and material of a Howe bridge under vertical loads. Specifically, it aimed to find out how small changes on Howe bridge design and material affected von Mises stresses as well as stresses at $Z$ direction. As a method, it was used a finite element analysis (linear-elastic) by Autodesk F-360. Half of a bridge was designed (one bridge side) and loaded with a central higher load and two equal smaller lateral loads. In essence, von Mises stresses $(\sigma)$ and stress at $Z$ direction $\left(\sigma_{z}\right)$ decreased on stresses values until a certain design change, which was proportional to a raise of mass due to beams added on the trusses. With a change of material to a lighter metal, from steel to aluminum, it was possible to overcome the mass drawback brought by steel and utterly possible to end up for a more effective design for a Howe truss bridge by applying minimal design changes.
\end{abstract}

Keywords: Howe truss bridge, numerical simulation, optimization.

\author{
Published Online: June 09, 2021 \\ ISSN: $2684-4451$ \\ DOI : 10.24018/ejphysics.2021.3.3.82
}

\section{J. A. Martins}

Waterloo, Canadá.

(e-mail: jairophd@gmail.com)

E. C. Romão*

University of São Paulo, São Paulo,

Brazil.

(e-mail: estaner23@usp.br)

*Corresponding Author

\section{INTRODUCTION}

Bridges are very important for worldwide economy since this equipment shorten distances, and ultimately raising productivity and making products possible to be delivered to even the most remote places [1], [2]. More specifically, trusses bridges, studied in this paper, produce a simple structural configuration for supporting loads overtime [3]. Actually, bridges are of such importance that a project such as designing them in many engineering programs in universities is used as a way to develop a demand for theory application as well as creativity.

It is quite common to have professors promoting competitions among their students with a task of designing and building a bridge by using Popsicle sticks. Such bridges once built are loaded by a hydraulic press other times by hanging a mass on it. Each student's team has to develop and build a bridge model that should withstand the highest load. When the students' building phase ends, comes a proof phase that usually becomes an open event when students cheer for their bridge in a very worth competition [4]. The students' team winner is that one that presents the stronger bridge, capable to carry the highest load. According to the same author, this competition challenges students to investigate bridge designs, construction and it aids them to research about strength of materials involved in the project.

There is another benefit raised by [5] who mentions that a project like a bridge serves as an engine for invention since it helps students to perform a range of professional, transferable, and social competences. He adds that, in order to produce a strong learning environment for students, and at the same time making time for other important projects, it is important to start with a simple, but effective bridge design truss as a reference, a so-called Howe truss bridge. When it comes to design, a Howe truss bridge is defined by [6]as an upper and lower "chord", where each chord consisting of two parallel beams and each chord parallel to one another. The web consists of verticals, braces, and counterbraces. Vertical posts connect the upper and lower chords to another and create "panels" [7].

In practical terms, [8] compared two physical models and measured their stress levels experimentally. The author used software ANSYS as a tool and as a reference on his study and built a physical model for each bridge. Thereafter, he installed strain gages on specific locations of the models to measure forces. He demonstrated experimentally that Howe bridge experiences the lowest maximum compression force on any beam when compared with Pratt bridge model. Based on all research described previously, a Howe truss bridge was chosen for this study.

This research proposes an effective change on the Howe Bridge design by adding elliptic beam plus additional beams on the bridge aiming to reduce stresses. Furthermore, checking how stresses are proportional to the mass change, and finally how a switch to a lighter material can help to reach a simple notwithstanding ideal Howe truss bridge. To sum up, this paper aimed to determine an ideal stress versus mass combination for a Howe bridge by using Autodesk F360 to test design changes and different materials. 


\section{MATERIALS AND METHODS}

This paper is a theoretical model study that articulates changes on a Howe bridge design and material and analyzes results from those changes. A software called F360 by Autodesk was used as a tool to determine the von Mises stresses $(\sigma)$ and stresses on $Z$ direction $\left(\sigma_{z}\right)$ on beams. The von Mises was chosen since it represents the result of a matrix of all tensors applied on the structure (axis and planes) and $\mathrm{Z}$ direction was chosen since it is exactly the direction the loads are applied. In order to run the static stress simulation, based on stiffness, Hooke's equation was used, that for the Solid Mechanics calculation, it respected the equations by [9] we have:

$0=\nabla \cdot S+F_{V} \quad \therefore \quad S=S_{a d}+C / \varepsilon_{e l}$,

being $\varepsilon_{e l}=\varepsilon-\varepsilon_{\text {inel }}$ and

$S_{a d}=S_{0}+S_{\text {ext }}+S_{q}$ and

$\varepsilon_{\text {inel }}=\varepsilon_{0}+\varepsilon_{t h}+\varepsilon_{h s}+\varepsilon_{p l}+\varepsilon_{c r}$

$\therefore \quad \varepsilon=\frac{1}{2}\left[(\nabla u)^{T}+\nabla u\right]$

where $\nabla . S=$ Cauchy stress tensor $(\mathrm{MPa}), F_{V}=$ volume force $(\mathrm{N}), \varepsilon_{0}=$ Initial strain (dimensionless), $\varepsilon_{t h}$ Thermal strain (dimensionless), $\varepsilon_{h s}=$ Hygroscopic strain (dimensionless), $\varepsilon_{p l}$ $=$ Plastic strain (dimensionless), $\varepsilon_{c r}=$ Creep strain (dimensionless), $\varepsilon_{v p}=$ Viscoelastic strain (dimensionless), $S_{0}$ $=$ Initial stress tensor $(\mathrm{MPa}), S_{\text {ext }}=$ External stress tensor (MPa), $S_{q}=$ Extra stress due to viscous damping ( $\left.\mathrm{MPa}\right), S_{a d}=$ deviatoric stress $(\mathrm{MPa}), \varepsilon=$ linear strain-displacement (dimensionless). $\varepsilon_{e l}\left(=\varepsilon-\varepsilon_{\text {inel }}\right)$ elastic strain (dimensionless), represents the total strain minus initial and inelastic strains, such as thermal strains.

Equations above are linked and based on part's stiffness; Hooke's equation was used, as described below:

$F=k \cdot x \quad$ and

$\sigma=E . \varepsilon$

where $F=$ force $(N), k=$ constant stiffness $(\mathrm{N} / \mathrm{mm}), x=$ extension or compression distance (mm), $\sigma=$ stress (MPa), $E$ $=$ Young modulus $(\mathrm{MPa})$ and $\varepsilon=$ strain (dimensionless).

When it comes to dimensions adopted to a Howe truss bridge, Fig. 1 shows the bridge in detail.

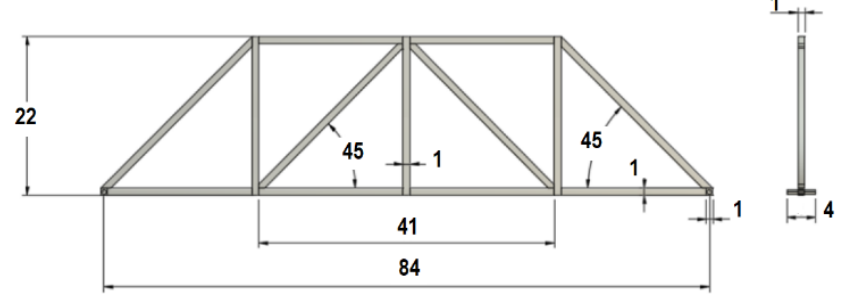

Fig. 1. Howe Truss Design $(\mathrm{H})-$ dimensions in $(\mathrm{mm})$.

The first step was to design and simulate numerically a Howe truss bridge, evaluate von Mises stress $(\sigma)$ and stresses at $Z$ direction $\left(\sigma_{z}\right)$ and have it as a reference (Fig. 1). A second step was to add an ellipse beam at the center of the vertical beam on the horizontal beam thereafter to run a numerical simulation. Afterwards, for another simulation, two beams item 2 were added to create an anchoring on the inclined beam sitting on the ellipse. As a final step, reinforcements were added on inclined beam at the extremes of Howe truss beam (item 3). All simulations aimed to check the real benefits in terms of lowering stresses when additional elements put on the structure (Fig. 2) and thereafter comparing them with Howe truss bridge. It is important to highlight that the same beam cross section was kept, which was a square with a side equal of $1 \mathrm{~mm}$. Pins on the frame structure had diameter 1 and length 4 , as shown at Fig. 1.

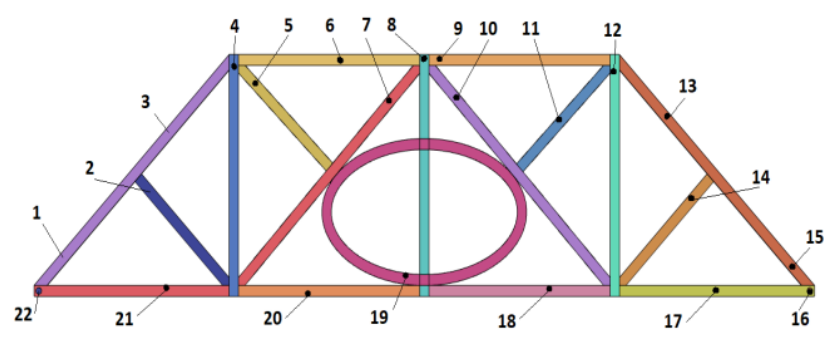

Fig. 2. All beams added on the Howe Bridge - elliptic beam (1) plus 2 beams (2) and additional beams (3) (HEB2R).

For a better understand, mainly when looking at FEA results, a few acronyms were utilized as described at Table I.

TABLE I. ACRONYMS BASED ON BRIDGE DESIGN

\begin{tabular}{cccc}
\hline Acronym & Description & $\begin{array}{c}\text { Figure } \\
\text { Number }\end{array}$ & $\begin{array}{c}\text { Beams } \\
\text { added }\end{array}$ \\
\hline $\mathrm{H}$ & $\begin{array}{c}\text { Regular Howe Bridge Design } \\
\text { Howe Bridge with an Elliptical } \\
\text { Beam }\end{array}$ & 1 & Reference \\
HEB1R & $\begin{array}{c}\text { Howe Bridge with an Elliptical } \\
\text { Beam and 1 pair of } \\
\text { reinforcement beams }\end{array}$ & 8 & 5 and 11 \\
HEB2R & $\begin{array}{c}\text { Howe Bridge with an Elliptical } \\
\text { Beam and 2 pair of } \\
\text { reinforcement beams }\end{array}$ & 2 & 2 and 14 \\
\hline
\end{tabular}

When it comes to loads, a force of $40 \mathrm{~N}$ was applied to the central beam and two equal forces of $20 \mathrm{~N}$ were applied on both the lateral vertical beams as shown at Fig. 3. The numerical simulation imposes constraint on both lateral pins locking them for radial and axial movements. In terms of results, the measurement aimed to know; von Mises stress $(\sigma)$, Stress at $Z$ direction $\left(\sigma_{z}\right)$ and mass of each different design and for two different materials. A meshing was generated for mesh-based size settled at $6 \%$ for a scale mesh per part and an element order parabolic. Furthermore, a maximum run angle on curves was adjusted for $60 \%$, a maximum adjacent mesh size ratio of 1.5 , also a maximum aspect ratio of 10 and a minimum element size (\% of the average size) established at 20 .

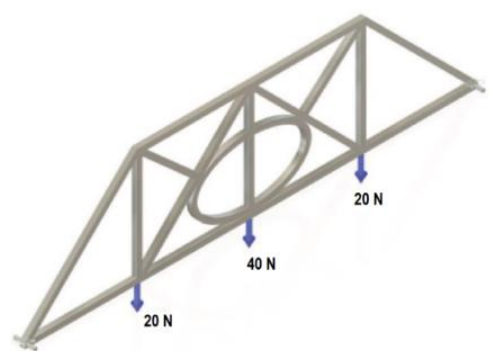

Fig. 3. Distribution of vertical loads. 


\section{RESULTS}

Simulation with a regular Howe design $(\mathrm{H})$, in Fig. 4 shows highest von Mises stresses at the upper and back face of the inclined lateral beams, items 13 and 3 , and it was close to 82 $\mathrm{MPa}$ (Fig. 4) while the highest $\sigma_{z}$ stress is found at the vertical beam item 12 and 4, being close to $76 \mathrm{MPa}$, as shown in Fig. 5 .

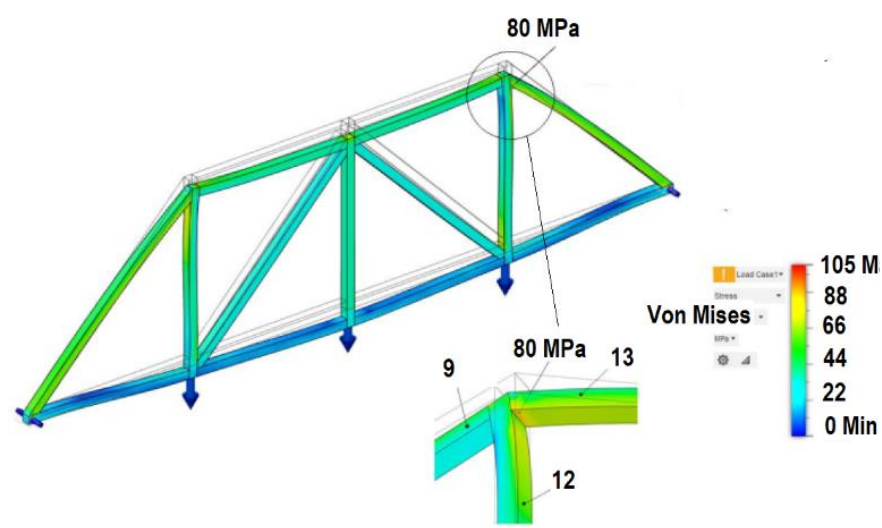

Fig. 4. von Mises stress for Howe Truss Bridge (H).

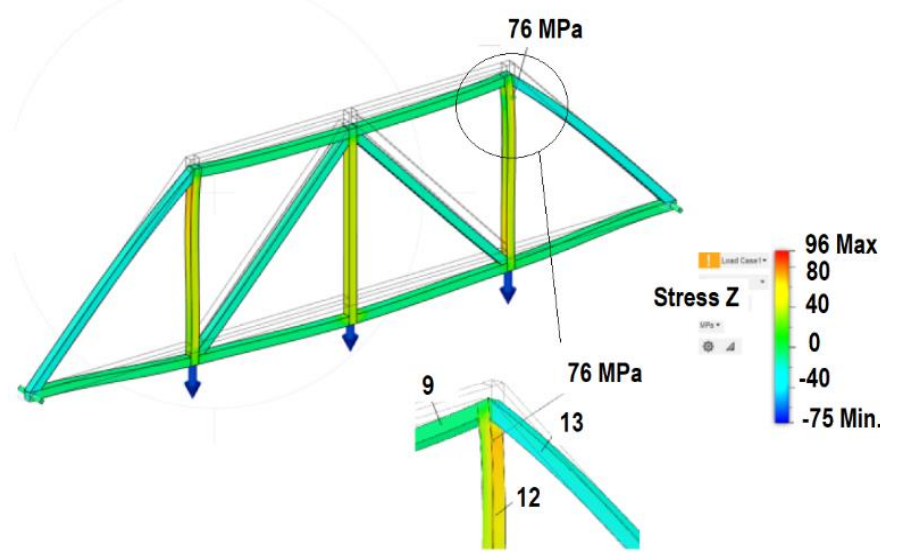

Fig. 5. Stress at $Z$ direction $\left(\sigma_{z}\right)$ for Howe Truss Bridge $(H)$.

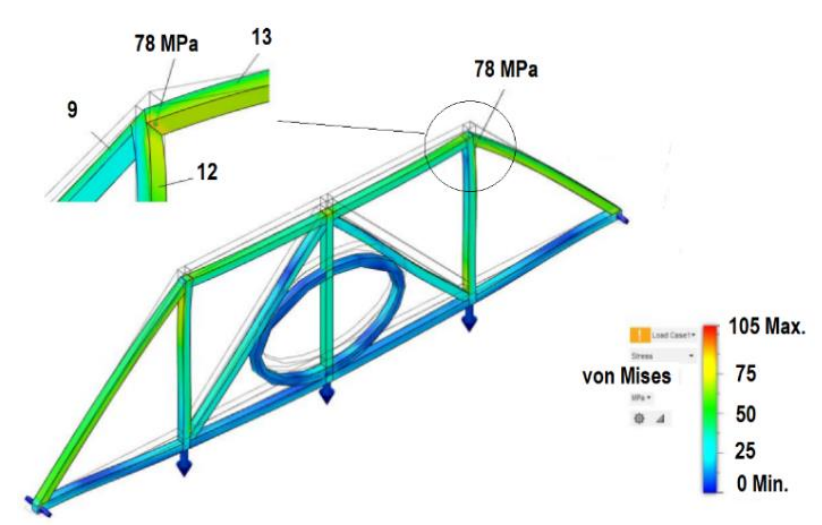

Fig. 6. von Mises stress for Howe Truss Bridge with an elliptic beam added (HEB).

When an elliptic beam (HEB) was added on the Howe design, beams 13 and 3 had the same region with the highest von Mises stress only the value slightly went down to $78 \mathrm{MPa}$ (Fig. 6). A change on the $Z$ stress (beam 12 and 4) also is present in this design. However, the stress intensity dropped from $76 \mathrm{MPa}$ from design $\mathrm{HE}$ to $75 \mathrm{MPa}$ to $\mathrm{HEB}$, which can be considered neglectable (Fig. 7).

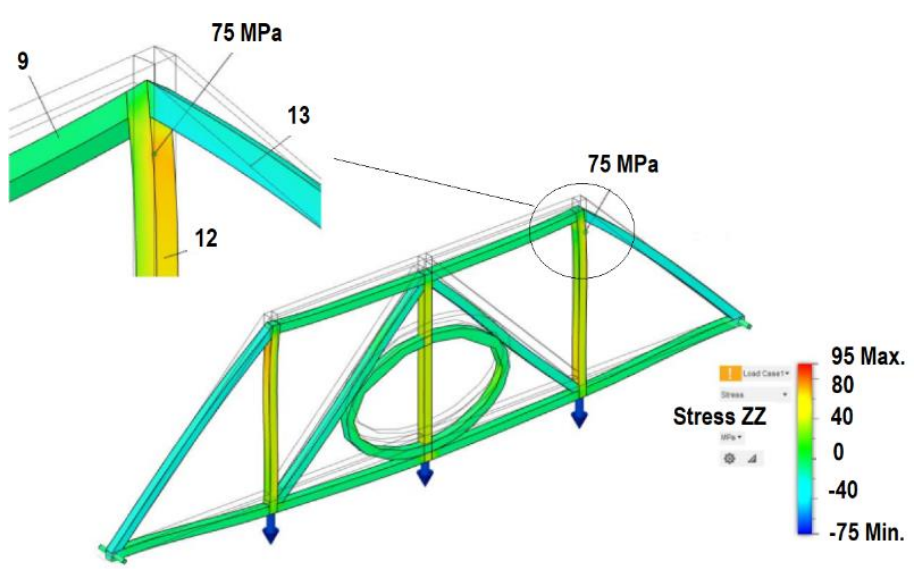

Fig. 7. Stress at $Z$ direction $\left(\sigma_{\mathrm{z}}\right)$ for Howe Truss Bridge with an elliptic beam added (HEB).

When it comes to HEB1R where two extra beams items 11 and 5 were added, the von Mises stress raised substantially and reached $108 \mathrm{MPa}$ at items 3 and 13 (Fig. 8), close to its connection to their vertical beam item 4 and 12 . Conversely, stress at $Z$ direction dropped from HEB to HEB1R from 75 to $65 \mathrm{MPa}$ (Fig. 9) but both were found at the beam's items 4 and 12 .

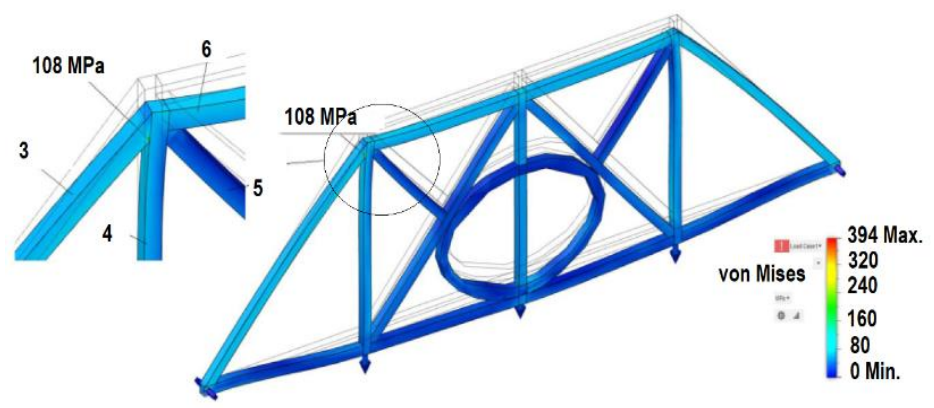

Fig. 8. von Mises stress for Howe Truss Bridge with an elliptic beam and reinforcement beam (HEB1R).

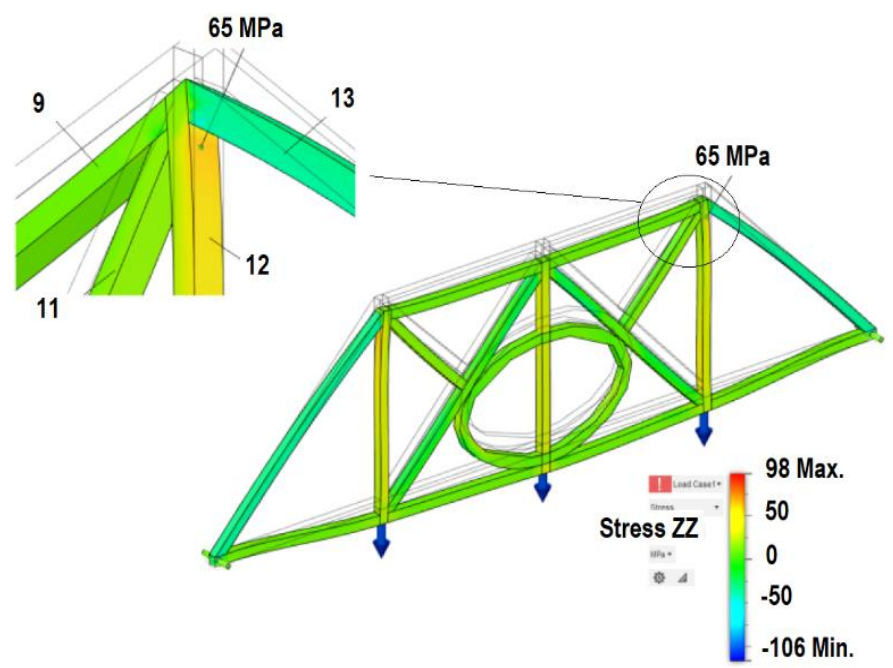

Fig. 9. Stress at $\mathrm{Z}$ direction $\left(\sigma_{\mathrm{z}}\right)$ for Howe Truss Bridge with an elliptic beam and reinforcement beams (HEB1R).

The final design change HEB2R presented the highest von Mises stress $95 \mathrm{MPa}$ (Fig. 10), verified at beam item 13 and 3 differently from HEB1R that had highest stress present at item 12 and 4 . The stress at $Z$ direction also dropped from 65 
to $63 \mathrm{MPa}$ (Fig. 11), not significantly, but at the same beam, item 4 and 12.

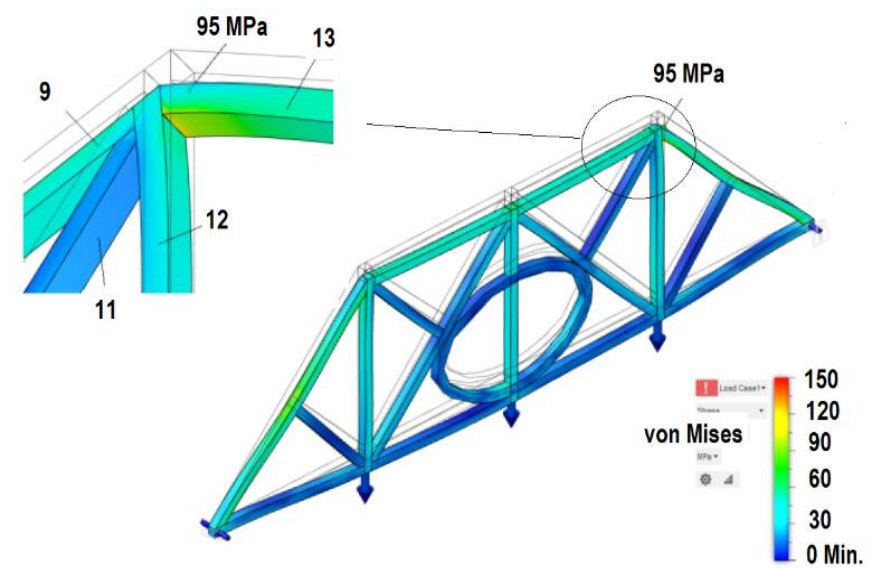

Fig. 10. von Mises stress for Howe Truss Bridge with an elliptic beam and two reinforcement beams (HEB2R).

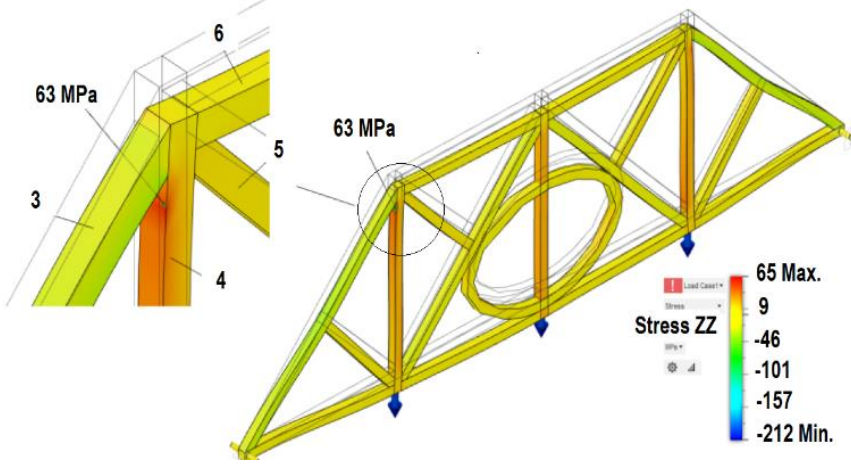

Fig. 11. von Mises stress for Howe Truss Bridge with an elliptic beam and two reinforcement beams (HEB2R).

An important piece of information to consider is that no matter the design, the higher von Mises stresses $(\sigma)$ are higher on the vertical beams (items 12 and 4) and on the inclined lateral beams (items 3 and 13) than the horizontal beam at the bottom of structure or elliptical beam installed.

In Tables II and III show the stresses output from all finite analysis simulations. In specific, the tables show the percentage differences between them, and the mass linked with each design, when material was changed from steel to aluminum. Furthermore, column percentage (\%) takes Howe bridge stress value as a reference to calculate the other designs while column $1 \%$ demonstrates the difference between the stress found against immediate anterior bridge design in terms of stress and mass.

As can be seen at Table II and Fig. 14 the von Mises stress had a slight decrease when an elliptical beam was added, not substantial ( $2 \mathrm{MPa}$ ) for steel beams while stress at $Z$ direction lowered $1 \mathrm{MPa}$, which is not substantial, representing a decrease of only $1 \%$. When inclined beams were inserted (5 and 11) there was a peak in von Mises stress, an impressive raise of $35 \%$ from the previous design (HEB) while the $Z$ stress decreased $10 \mathrm{MPa}$. When the final design was implemented (HEB2R) with another pair of beams added (2 and 14) von Mises stress dropped 12\%, from 108 to $95 \mathrm{MPa}$. Differently, $Z$ stress lowered only $2 \mathrm{MPa}$, from 65 to $63 \mathrm{MPa}$.

When the material was changed from steel to aluminum von Mises stress for designs HE lowered $8 \mathrm{MPa}$ when compared with steel for the same design. It went from 80 to $72 \mathrm{MPa}$. Stress at $Z$ direction was changed from $76 \mathrm{MPa}$ for steel against $72 \mathrm{MPa}$ for aluminum. For the design HEB steel and aluminum had almost de same von Mises stresses (78 MPa for steel against $82 \mathrm{MPa}$ for aluminum) also $Z$ stresses (75 MPa for steel against $74 \mathrm{MPa}$ for aluminum). Reaching the design HEB1R the von Mises stress for aluminum raised from $82 \mathrm{MPa}$ to $89 \mathrm{MPa}$ but when compared with steel it was lower, $108 \mathrm{MPa}$ for steel against $89 \mathrm{MPa}$ to Aluminum.

In the final design the von Mises stress for aluminum raised from $89 \mathrm{MPa}$ to $116 \mathrm{MPa}$ while $Z$ stress raised only $2 \mathrm{MPa}$, from $60 \mathrm{MPa}$ to $62 \mathrm{MPa}$. When it is compared with steel, aluminum von Mises stress was higher (95 MPa for steel while $116 \mathrm{MPa}$ for aluminum). When it comes to $\mathrm{Z}$ stress the stresses were almost the same $63 \mathrm{MPa}$ for steel and $62 \mathrm{MPa}$ for aluminum.

By comparing Table II (Steel) and Table III (Aluminum), it's possible to note the wide benefit when using aluminum when compared to steel. It is based on the specific mass difference between materials. In terms of mass, there is an impressive gain on the structure mass.

\begin{tabular}{ccccccccc}
\multicolumn{7}{c}{ TABLE II: SiMULATIONS OUTPUT - STEEL } \\
\hline $\begin{array}{c}\text { Design - } \\
\text { Steel }\end{array}$ & $\begin{array}{c}\text { von Mises } \\
(\mathrm{MPa})\end{array}$ & $\%$ & $\% 1$ & $\begin{array}{c}\text { Z direction } \\
(\mathrm{MPa})\end{array}$ & $\%$ & $\begin{array}{c}\text { Mass } \\
(\mathrm{kg})\end{array}$ & $\%$ & $\begin{array}{c}\% \\
1\end{array}$ \\
\hline H & 80 & & & 76 & & 2.376 & & \\
HEB & 78 & -2.5 & & 75 & -1.3 & 2.801 & 17.9 & \\
HEB1R & 108 & 35.0 & 38.5 & 65 & -14.5 & 3.012 & 26.8 & 7.5 \\
HEB2R & 95 & 18.8 & -12.0 & 63 & -17.0 & 3.226 & 35.8 & 7.1 \\
\hline
\end{tabular}

\begin{tabular}{ccccccccc}
\multicolumn{8}{c}{ TABLE III: SIMULATION's OUTPUT - ALUMINUM } \\
\hline $\begin{array}{c}\text { Design - } \\
\text { Aluminum }\end{array}$ & $\begin{array}{c}\text { von Mises } \\
(\mathrm{MPa})\end{array}$ & $\%$ & $\% 1$ & $\begin{array}{c}\text { Z direction } \\
(\mathrm{MPa})\end{array}$ & $\%$ & $\begin{array}{c}\text { Mass } \\
(\mathrm{kg})\end{array}$ & $\%$ & $\begin{array}{c}\% \\
1\end{array}$ \\
\hline H & 72 & & & 72 & & 0.82 & & \\
HEB & 82 & 14.1 & & 74 & 2.8 & 0.96 & 17.1 & \\
HEB1R & 89 & 23.6 & 8.5 & 60 & -16.7 & 1.03 & 25.6 & 7.3 \\
HEB2R & 116 & 61.1 & 30.3 & 62 & -14 & 1.11 & 35.4 & 7.8 \\
\hline
\end{tabular}

\section{CONCLUSION}

This research proposed a change on the Howe Bridge design by adding a central elliptic beam plus additional beams on the bridge aiming to ideal stresses and mass combination. Furthermore, checking how stresses might be proportional to the mass change, and finally how a switch to a lighter material can help to reach a simple notwithstanding ideal Howe truss bridge.

According to stress evaluation, von Mises stress $(\sigma)$ and stress at $Z$ direction $\left(\sigma_{z}\right)$ and mass, the Howe truss bridge with an elliptical beam (HEB) was superior to the original Howe 
bridge $(\mathrm{H})$ since there was a small change of stress levels but it carried a large benefit in terms of mass when the material was switched to aluminum.

When two additional beams were added on the last design (HEB) in a way that they supported indirectly the elliptical beam (design HEB1R), the stresses on the beams with aluminum material was inferior to steel. For aluminum, HEB1R presented a slight increase of stress when compared with the last design HEB as well.

The last design change HEB2R made from aluminum is inferior of the previous design (HEB1R) because stresses were higher than the previous configuration and substantially higher than the original Howe bridge design, even made of steel. For HEB2R made of steel the stress decreased but it is still $18 \%$ higher than original design.

To sum up, the switch of material from steel to aluminum ended up as a good solution since it has less mass to Howe design. The best combination that brought the ideal stress with less mass was Howe design with an elliptical beam added at the centre of the structure. The additional designs changes added substantial stress on the structure for both materials.

\section{REFERENCES}

[1] Bridge Masters Bridge Work, B. a. (2018, March 16). BMI Bridge Master Rentals. Retrieved from The Positive Economic Impacts of Bridges: https://bridgemastersinc.com/positive-economic-impactsbridges/\#: :text=\%231\%20\%E2\%80\%93\%20Bridges $\% 20$ are $\% 20 \mathrm{a} \%$ 20critical,their\%20own\%20communities\%20and\%20beyond.

[2] Arturo Gonzalez, M. S. (2020). Bridges: Structures and Materials, Ancient and Modern, Infrastructure Management and Construction. In F. T. Samad M.E. Sepasgozar, Infrastructure Management and Construction. IntechOpen. https://www.intechopen.com/books/infrastructure-management-andconstruction/bridges-structures-and-materials-ancient-and-modern.

[3] Okonkwo, V. O., Onodagu, P. D., \& Udemba, J. N. (2021). An Investigation ontheEffects ofRigid Joints ontheWeight andLoad Carrying Capacity ofSteel Trusses. IOSR Journal of Engineering (IOSRJEN), 33-39.

[4] Chang, G., \& Peterson, W. (2009). AC 2009-1301: BRIDGE DESIGN PROJECT: A HANDS-ON APPROACH TOSTATICS AND STRENGTH OF MATERIALS LEARNING. American Society for Engineering Education.

[5] O'Kelly, B. C. (2007). CASE STUDY OF A PROBLEM-BASED BRIDGE ENGINEERING DESIGN COURSE. International Symposium for Engineering Education. Dublin City University, Ireland.

[6] Waddel, J. A. (1916). Bridge Engineering . New York: John Wiley \& Sons.

[7] Merriman, M., \& Jacoby, H. S. (1919). A Text-Book on Roofs and Bridges. Part I: Stresses in Simple Trusses. New York: John Wiley \& Sons.

[8] William Berry, K. D. (2019). Model Truss Bridge Design. West Kentucky.

[9] Kaltenbacher, M., \& Triebenbacher, S. (2013). Advanced Finite Element Schemes for Multiphysic. International Conference on Sensors and Measurement Technology . AMA Verband fur Sensorik+Messtechnik.

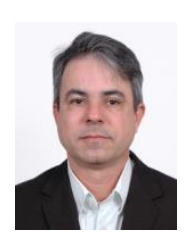

Jairo A Martins is a Doctor in Philosophy (Ph.D.) in Mechanical Engineering by University of State of Campinas (Unicamp) in 2004 and post-doctoral fellow at University of São Paulo (USP) 2016, both in Brazil. He works as Research \& Development Manager at DESCH in Canada. Dr. Martins main field of study is mechanics and material science, among them; machine engineering design, x-ray diffraction, residual stress, fracture, fatigue, finite element analysis (linear and non-linear) and manufacturing processes.

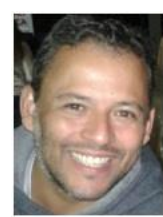

Estaner Claro Romão is a Doctor in Philosophy (Ph.D.) in Mechanical Engineering by University of State of Campinas (Unicamp) in 2011 and post-doctoral fellow at UNICAMP 2013, both in Brazil. He currently works in two lines of research: Teaching Mathematics and Science and Numerical Simulation of Transfer Problems and Heat and Mass and Solid Mechanics. He is currently an Associate Professor at the University of São Paulo, Escola de Engenharia de Lorena. 